\title{
BMJ Open Socioeconomic differences in experiences with treatment of coronary heart disease: a qualitative study from the perspective of elderly patients
}

\author{
Sara Lena Schröder, Astrid Fink, Matthias Richter
}

To cite: Schröder SL, Fink A, Richter M. Socioeconomic differences in experiences with treatment of coronary heart disease: a qualitative study from the perspective of elderly patients. BMJ Open 2018;8:e024151. doi:10.1136/ bmjopen-2018-024151

- Prepublication history and additional material for this paper are available online. To view these files, please visit the journal online (http://dx.doi org/10.1136/bmjopen-2018024151).

Received 11 May 2018 Revised 26 July 2018 Accepted 28 September 2018

Check for updates

(c) Author(s) (or their employer(s)) 2018. Re-use permitted under CC BY-NC. No commercial re-use. See rights and permissions. Published by BMJ.

Institute of Medical Sociology, Martin Luther University HalleWittenberg, Medical Faculty, Halle (Saale), Germany

Correspondence to Sara Lena Schröder; sara.schroeder@medizin.unihalle.de

\section{ABSTRACT}

Objectives This qualitative study aims to analyse socioeconomic differences in patients' experiences along the treatment pathway for coronary heart disease (CHD). Design A longitudinal qualitative study using in-depth semistructured interviews to explore patients' experiences with treatment was conducted. We analysed the transcripts of the records according to qualitative content analysis and identified differences between patients with lower and higher socioeconomic status (SES) by comparing and contrasting the narratives.

Setting The University Hospital in Halle (Saale), Germany. Participants 41 elderly patients (aged 59-80 years) who suffered from CHD.

Results From various patient's experiences along the pathway of care which were found to differ according to SES we derived three major themes: (1) information: patients with higher SES had greater knowledge about treatment and could use medical records as sources of information; (2) illness perception: patients with lower SES focused on improving symptoms and survival, while patients with higher SES focused on physical performance and disease management; and (3) perceived role in healthcare: patients with lower SES tended to delegate responsibility to healthcare professionals.

Conclusions Differences in the patient's knowledge about treatment, their perceived role in healthcare and illness perception can be the factors and mechanisms that contribute to explain socioeconomic inequalities in the treatment of CHD. These factors should be considered in quantitative studies to better understand the disparities in treatment and mortality. We suggest that improving patient-physician communication and patient knowledge can change the patient's understanding of CHD and their perceived role in healthcare and reduce inequalities in CHD treatment.

Trial registration number DRKS00007839.

\section{INTRODUCTION}

Coronary heart disease (CHD) remains the leading cause of death worldwide. ${ }^{1-3}$ Treatment of CHD includes revascularisation, rehabilitation and long-term medication and aims to improve disease-related quality of life, including exercise capacity, to prevent

\section{Strengths and limitations of this study}

- The longitudinal design enabled us to collect information regarding the patient's experiences along the treatment pathway for coronary heart disease from a first revascularisation to aftercare.

- We performed a comparative analysis to explore differences between patients with lower and higher socioeconomic status regarding their perspectives and experiences with treatment.

- Generalisability in this study might be limited as we only recruited elderly patients in a large city in the Eastern part of Germany; therefore, the results may not reflect the experiences of younger patients with coronary heart disease or those in countries without universal healthcare systems.

further cardiac events and reduce mortality. Socioeconomic inequalities in the incidence and mortality of CHD, to the disadvantage of patients with low socioeconomic status (SES), have been well explored. ${ }^{4-6}$ Therefore, patients of low SES have a greater need for treatment. Access to treatment is aimed to be on the basis of need rather than of gender, residence or SES, and guidelines note the importance of reducing inequalities in healthcare. ${ }^{7}$ However, several studies showed strong socioeconomic differences in CHD treatment, to the disadvantage of patients with low SES. ${ }^{8}$

How inequalities in healthcare arise is complex and largely unknown. As socioeconomic differences in treatment are provable regardless of the underlying healthcare system, they may be attributable to reasons other than financial affordability of healthcare costs. ${ }^{8}$ This is particularly the case in countries such as Germany, where individuals have statutory health insurance and very low out-of-pocket payments. In cardiac rehabilitation, a recent study found that comorbidities, self-efficacy, anxiety and depression, 
cohabitation, commute, disease severity or type of treatment do not significantly mediate the association of SES with attendance and participation. ${ }^{9}$ However, health literacy and communication between physician and patient are discussed to generally explain healthcare inequalities, as they are strongly associated with SES. ${ }^{10-12}$ Although there is no clear evidence regarding whether an increase in treatment rates reduces socioeconomic disparities in access to treatment, ${ }^{13}{ }^{14}$ Perelman et al found that socioeconomic inequalities in CHD treatment can be partly explained by different distances to hospitals with on-site cardiac facilities. ${ }^{15}$

Therefore, the underlying causes and determinants of socioeconomic inequalities in CHD treatment are still not fully understood or analysed. Taking the patients' individual needs and perceptions into account is helpful to reveal new explanatory approaches from the patient's perspective and explore how socioeconomic differences might arise. Qualitative research aims to understand healthcare interactions from the patient's perspective and can help to identify the mechanisms that lead to inequalities in healthcare. To our knowledge, there are only two qualitative studies exploring socioeconomic differences in the treatment of CHD. Manderbacka analysed differences in healthcare encounters and found that doctor-centred decision-making was more common in lower-SES patients. ${ }^{16}$ Pedersen et al found that concerning barriers to cardiac rehabilitation, only lower-SES patients felt excluded due to their divergent health beliefs. ${ }^{17}$ To gather scientific evidence on the possible factors and mechanisms of socioeconomic inequalities in CHD treatment, we aimed to identify socioeconomic differences in the patient's perspective and their experiences with the treatment pathway for CHD in all sectors from therapy to aftercare.

\section{MATERIAL AND METHODS Study design}

Based on the methodology of grounded theory, we conducted an exploratory qualitative longitudinal study of elderly patients with CHD to examine socioeconomic differences in access, utilisation and quality of treatment. ${ }^{18}$ A purposive sampling strategy was used to select patients with a confirmed diagnosis of CHD at a university hospital in Germany. Additionally, the patients had to fulfil the inclusion criteria of being between 60 and 80 years and having one additional principal or secondary diagnosis of stable angina pectoris, acute coronary syndrome or cardiac arrhythmia. Patients were excluded from the study if they had insufficient language skills to conduct an interview in German language or were moribund. Between November 2014 and April 2015, a study nurse contacted patients who were hospitalised in the department of cardiology, informed them through a flyer and explained the purpose of the study. We approached 96 eligible patients and asked them to attend an interview to share their experiences with CHD treatment. Participation was voluntary, the patients received no incentives, and 61 patients agreed to participate. Of those, we gradually chose 48 for an interview in accordance with maximum variation to assure that men and women with different SES and different CHD severities (number of atherosclerotic altered vessels, type of revascularisation needed, and manifestations of angina pectoris or myocardial infarction) were represented who covered a broad spectrum of treatment experience. To achieve maximum variation, we also included one 59-year-old patient because of relevant experiences. After 48 interviews, theoretical saturation in terms of experiences with diagnosis and treatment of different CHD severities was reached. We stopped recruiting new interviewees when the experiences of new interviews were very similar to the narratives reported earlier by other patients, and no new categories emerged during inductive coding. After 6 months, we contacted the 48 participants again and asked them to participate in a follow-up interview. Eight patients refused to participate due to their disease burden, lack of interest or failure to respond to the invitation letter, and one patient was no longer alive. The 39 follow-up interviews were conducted between June and October 2015.

\section{Data collection}

We conducted semistructured interviews to explore the patients' perspectives on their heart disease and their personal experiences with the treatment they received. The interview guide (see online supplementary S1 appendixS1 appendix) was developed according to Helfferich with key questions that evoke narrations which were derived from the state of research. ${ }^{19}$ To cover the same topics within each interview, these key questions were supplemented by specific questions which were only asked if not mentioned by the patient himself. The key and supplementary questions were developed by a process of collecting, checking, sorting and subsuming topics and questions of relevance in accordance with the research question and aim. SLS conducted two preliminary interviews that were used to further develop the semistructured interview guides. We began the baseline interviews with a broad general question about the medical history. More detailed questions were asked individually based on each patient's narrative. All Interviews were conducted and analysed in German language. For the Quotations and interview guide presented in this manuscript we conducted a double-blind translation from German to English that was checked by a third person. The patient's basic sociodemographic data were obtained with a short, standardised questionnaire following the baseline interview, and the interviewer subsequently wrote a field note for each interview.

Baseline interviews were conducted in a private room of the hospital, and follow-up interviews were held either at the patient's home or at the medical facility, depending on the patient's choice. Two employees of the Institute of Medical Sociology (IMS) conducted the interviews face-to-face: SLS (female) is a research 
associate and an economist who has conducted qualitative health research since 2009 and conducted most of the interviews; Nils Bormann (male) is a medical student assistant and an economist who was trained prior to conducting the interviews. The interviewers introduced themselves as members of the IMS, not working in the department of cardiology. Each baseline interview included only the patient and one or both interviewers. In some follow-up interviews, family members were present at the patient's request. The interviews lasted an average of $35 \mathrm{~min}$ at baseline and $42 \mathrm{~min}$ at follow-up and were audio-taped with the interviewee's permission.

SES was defined by educational level and occupation based on the German epidemiological standards. ${ }^{20}$ Education was measured by level of schooling and academic qualifications and was classified on an 8-point scale. Occupation was measured by the last occupational group the patient belonged to and classified according to job autonomy on a 5-point scale. ${ }^{21}$ A composite index of SES was derived using a sum score of both items which ranged between 2 and 13. Index values between 2 and 7 were rated 'lower SES', and values between 8 and 13 were rated 'higher SES'.

\section{Data analysis}

After constructing the main categories that originated from the research questions, SLS coded the pseudonymised interview transcripts in a data-driven approach (inductively) sentence by sentence with codes and themes derived from the data in accordance with qualitative content analysis. ${ }^{22}$ The coding started simultaneously with the conducting of the interviews. Five contrasting transcripts were double-coded by two additional members of the qualitative research working group at the IMS, who also participated in the discussion and evaluation of the data. The working group was composed of researchers with different backgrounds, namely, sociology, healthcare research, economics, nursing and educational science. The emerging codes were organised into subcategories with the existing main categories. Afterwards, we identified socioeconomic differences by comparing and contrasting the codes of the frame between patients with lower and higher SES. Codes that were found only in one group constituted the origin of comparing and contrasting the narratives to identify SES-specific patient perspectives and experiences in each phase of treatment. Building on these results, we constructed overall major themes which characterised the differences across the continuum of care. We used MAXQDA V.11 software to assist with the data management and analyses. In the present analysis, we excluded seven patients because neither CHD nor any CHD-indicative treatment was mentioned throughout their interviews as the narratives of treatment experiences had been overshadowed by other heart diseases. Additionally, to the 41 baseline interviews, we included the narratives of those 17 follow-up interviews in the current analysis which provided important additional information
Table 1 Characteristics of the patients at baseline $(n=41)$

\begin{tabular}{llll}
\hline Characteristics & $\begin{array}{l}\text { Number } \\
\text { in overall } \\
\text { patients }\end{array}$ & $\begin{array}{l}\text { Number in } \\
\text { lower-SES } \\
\text { patients }\end{array}$ & $\begin{array}{l}\text { Number in } \\
\text { higher-SES } \\
\text { patients }\end{array}$ \\
\hline Total & 41 & 23 & 18 \\
\hline Age, the mean & 69.7 & 69.7 & 69.6 \\
\hline Male & 26 & 10 & 16 \\
\hline $\begin{array}{l}\text { Female } \\
\text { Publicly insured }\end{array}$ & 15 & 13 & 2 \\
\hline $\begin{array}{l}\text { One-vessel disease } \\
\text { Two-vessel disease }\end{array}$ & 13 & 23 & 18 \\
$\begin{array}{l}\text { Three-vessel } \\
\text { disease }\end{array}$ & 17 & 8 & 5 \\
$\begin{array}{l}\text { CHD diagnosed for } \\
\text { up to 1 year }\end{array}$ & 20 & 9 & 5 \\
$\begin{array}{l}\text { CHD diagnosed } \\
\text { longer than 1 year } \\
\text { ago }\end{array}$ & 21 & 13 & 8 \\
\hline
\end{tabular}

CHD, coronary heart disease; SES, socioeconomic status.

to answer the research question. In total, we analysed 58 interviews from 41 patients.

\section{Patient involvement}

By exploring patients' experiences with treatment in this study through an exploratory design, the patients' preferences and priorities led the data collection during the interviews and due to an inductive data-driven approach as well, throughout data analysis. The participants did not provide feedback on their transcripts or the findings.

\section{RESULTS}

This analysis was based on the transcripts of 58 interviews (41 baseline and 17 follow-up) with 41 patients. The baseline characteristics of the 41 patients are shown in table 1. Throughout the narratives, treatment of CHD was reported as a complex process with the involvement of many providers. The majority of the patients reported using treatment, for example, revascularisation at the hospital; inpatient cardiac rehabilitation; visiting their general practitioner (GP) regularly, who prescribes the medication as recommended from the hospital; and having regular appointments with a resident cardiologist. Only a few patients (from both SES groups) reported having problems with access to, utilisation of or quality of treatment. However, we found differences according to SES in the patients' individual perceptions and perspectives on treatment which are described separately hereafter subdivided into four sections: treatment at the hospital, rehabilitation, treatment with drugs and ambulatory aftercare. Quotations reflective of the differences are presented for patients of lower and higher SES at the various stages of treatment. Following three major themes, which were derived from the sector-specific 
differences, are depicted: 'information', the 'patient's individual perception of CHD' and the 'perceived role in healthcare'. These themes might characterise the factors and mechanisms of socioeconomic differences in treatment across the continuum of care.

\section{Treatment at the hospital}

With regard to revascularisation, some patients reported that a second coronary angiography (CAG) was scheduled and conducted within a few days for different reasons. However, only lower-SES patients did not scrutinise or mention the reason when a diagnostic-only CAG was followed by a second CAG with stent implantation. Additionally, whereas many patients of both lower and higher SES rated it important for hospital staff to be friendly, attentive and caring, predominantly lower-SES patients mentioned aspects of being taken seriously either positively (eg, taking preferences seriously, being asked how one feels) or negatively (eg, discussions about but not with oneself, no conversations at all). While assessing the quality of treatment, some lower-SES patients reported being discharged with open wounds after coronary artery bypass graft surgery. Generally, while assessing the quality of treatment, lower-SES patients tended to focus on symptom improvement, eliminating the need for visits to the doctor or improving survival, whereas higher-SES patients predominantly aimed to improve physical performance.

Well, in the hope that everything stays the same. Let's say that you are well. Well, getting around with it quite well, with no complications arising. As I said, that one may reach a slightly older age, not just until retirement, but perhaps even a bit longer. (Mr Lange, 60 years, lower SES)

Well, but then it came up with the heart and I myself had the feeling that it is probably the only thing that really gets you back on your feet. I was really feeling sluggish. So I did indeed make an effort to try to walk again quickly and to/I really did, but somehow in the end the energy was lacking. (Mr Lehmann, 63 years, higher SES)

Knowledge of different treatment options became apparent mainly in patients with high SES. However, an information deficit was found in some narratives, for example, patients reporting that they did not know the outcome of medical examinations; they were unaware of the treatment that had been performed; or they rated the medical reports incomprehensible. An information deficit became apparent mainly in lower-SES patients, although this was not always experienced with a perceived greater need for information.

Yes, it has been explained to me, but I didn't get it. First of all, I sometimes didn't understand it, because he expressed himself in such a professional manner. The nurses already started laughing, because I/and then I thought: 'No, you better give up. You better read through it next time (Mrs Schubert, 80 years, lower SES)

For this there are, that's at least what has been explained to me, the clogged coronary arteries can be expanded by implanting stents, if you know what these are, incorporating these small tubes that eliminate the narrowed areas. Or if that is not feasible, which can happen as well that a vessel ruptures or something like that, then (...) it is done surgically. Then bypasses are produced from other parts of the body and incorporated.' (Mr Wagner, 75 years, higher SES)

We found paternalistic and shared decision-making in both SES groups, but paternalistic decisions were found to be more unquestioned in lower-SES patients, whereas higher-SES patients understood the reasons why decisions were made. When decisions were made jointly, we found that higher-SES patients were involved more actively in decision-making, whereas lower-SES patients thought of themselves as being only responsible for responding (agree or disagree) to a recommendation given.

With this I entirely relied on the physicians. In fact, I didn't really thought about it. When they said: 'This', then we do this. They do ask indeed: 'Mr. Zimmermann, do you agree?' I mean, when I go to the hospital, I let myself be treated, but this is not meant to be negative in any way. But I rely on the physicians. [...] They are the professionals. I would never pretend to be the wise guy, as I know people who do so, not physicians, but private persons, who dictate people what to do. (Mr Zimmermann, 76 years, lower SES)

Today, quite a few medical exams have been conducted with me. Now you have to wait, but I guess it won't change anything about this final decision. The demand placed on me to decide this. (Mr Hartmann, 69 years, higher SES)

\section{Cardiac rehabilitation}

Some patients reported whether the time interval between their discharge from hospital and the beginning of inpatient cardiac rehabilitation was either too long or too short for their individual needs. In doing so, only lower-SES patients reported they could not participate in therapeutic cardiac rehabilitation treatments due to their recent coronary artery bypass surgery, whereas only higher-SES patients focused their reasons on individual demands for disease management. Additionally, we found that while assessing the quality of cardiac rehabilitation, in the narratives of lower-SES patients, performing regular examinations, such as daily blood pressure measurement or ECGs, was more important, whereas higher-SES patients tended to place an emphasis on physical performance improvement, as well as increased knowledge about necessary behaviour changes and their heart disease in general. 
Indeed, in rehabilitation it was great. Well, there was/ everymorning you had to go to the presentation, weighing, measuring blood pressure and stuff like that. (Mrs Koch, 62 years, lower SES)

Over there I primarily learned through lectures and, as I said before, through meetings about what the issue of a heart attack means, how it emerges and so on. This improved much of my understanding. Previously, before you have something like that you don't care about it. So, concerning this matter one was educated quite well. (Mr Jung, 67 years, higher SES)

\section{Treatment with drugs}

Although specific drugs, agents or trade names were rarely mentioned throughout the narratives, access to and utilisation of any medications were fairly high in both SES groups. However, we found that with respect to medication preferences, some lower-SES patients highlighted the importance that the involved physicians should appropriately coordinate the selection of prescribed drugs, while some stated they generally did not like to take drugs. However, one higher-SES patient reported that he prefers to take combination medication.

Or, for example, if there are changes in medication, it is very important. With prothrombin time and everything; you need to be always in good hands. Not that one says this way and the other one says that way. That's bad. (Mr Köhler, 66 years, lower SES)

I have to take many drugs; they upset the stomach and everything. I had to take 17 or 18 different pills. Well, and then I recognized, I read about it, there is a patch and so on and using that you can come off of 5 drugs at once. The patches are indeed very expensive and the doctor immediately said 'no and no and no' and so on. Now I have this patch and I am feeling fine. (Mr Richter, 66 years, higher SES)

\section{Ambulatory aftercare}

Some patients in the lower-SES group mentioned undergoing regular check-ups every month with their GP to assess prothrombin time (Quick-test). While rating the quality of GPs, mainly lower-SES patients mentioned the importance of thorough medical examinations and doctor availability. Some mainly lower-SES patients reported about the GP examining or referring patients only on demand or the GP not helping them make an appointment with a cardiologist. Some predominantly lower-SES patients reported that they see themselves as responsible for retention of their medical record. However, some patients, mainly with higher SES, mentioned obtaining or inquiring for a recommendation from the GP regarding a particular specialist or hospital.

However, I wasn't correctly/Atfirst I didn't know something like that existed. Then, I asked my doctor. I say: 'Doesn't one have to go to any follow up?' - 'Well, I could forward you there, but you better try to make an appointment yourself’. (Mrs Körtig, 59 years, lower SES)

In one consultation it was like, 'To whom should I go?' And then he said, 'I have a number of colleagues here that I can recommend to you' And then I say, 'Alright, then make an appointment for me', and that's how I came to Mrs. Dr. Alpha. (Mr Winkler, 72 years, higher SES)

In addition, the patient's experiences with access to and utilisation of regular check-ups at a resident cardiologist varied according to SES. Some lower-SES patients perceived appointments with specialists as generally unnecessary or expected instructions from physicians about the necessity of appointments due to their own uncertainty. Some mainly higher-SES patients used medical reports as sources of information for the need of follow-up care.

As I said, I had to wait a very long time for this 24 hours ambulatory electrocardiogram. Then it was done. She [cardiologist] wrote her report, my GP got it and nothing else came of it. [...] I mean, if there would have been something acute, surely something would have come up, but it was still, that it is not/ (Mr Köhler, 66 years, lower SES)

I guess that I will have to go to my GP for follow up and he does further. [...] That is my current state. But I am not sure yet, because I have not received the medical report yet. I am still waiting for it. (Mr Schäfer, 71 years, higher SES)

\section{Factors and mechanisms of socioeconomic differences in CHD treatment}

While comparing the differences in the patients' experiences according to SES across the pathway of care, three major themes (figure 1) emerged to characterise differences and may be the factors and mechanisms for socioeconomic inequalities in CHD treatment, namely, information, patient's individual illness perception and their perceived role in healthcare.

First, the narratives suggest that lower-SES patients are less informed about their treatment than higher-SES patients which became apparent, for example, through their lack of knowledge regarding the treatment that was performed, as well as their lack of knowledge about the reasons for or outcomes of medical examinations. However, higher-SES patients knew about different treatment options. Whereas lower-SES patients reported they missed conversations at the hospital or rated the reports as incomprehensible, higher-SES patients explained that they use medical reports as sources of information. While most patients rated the healthcare system (especially hospitals) as overloaded, some made the connection that patients are given far too little information and are required to actively request information because of excessive work demands on health workers due to the healthcare system economisation. 


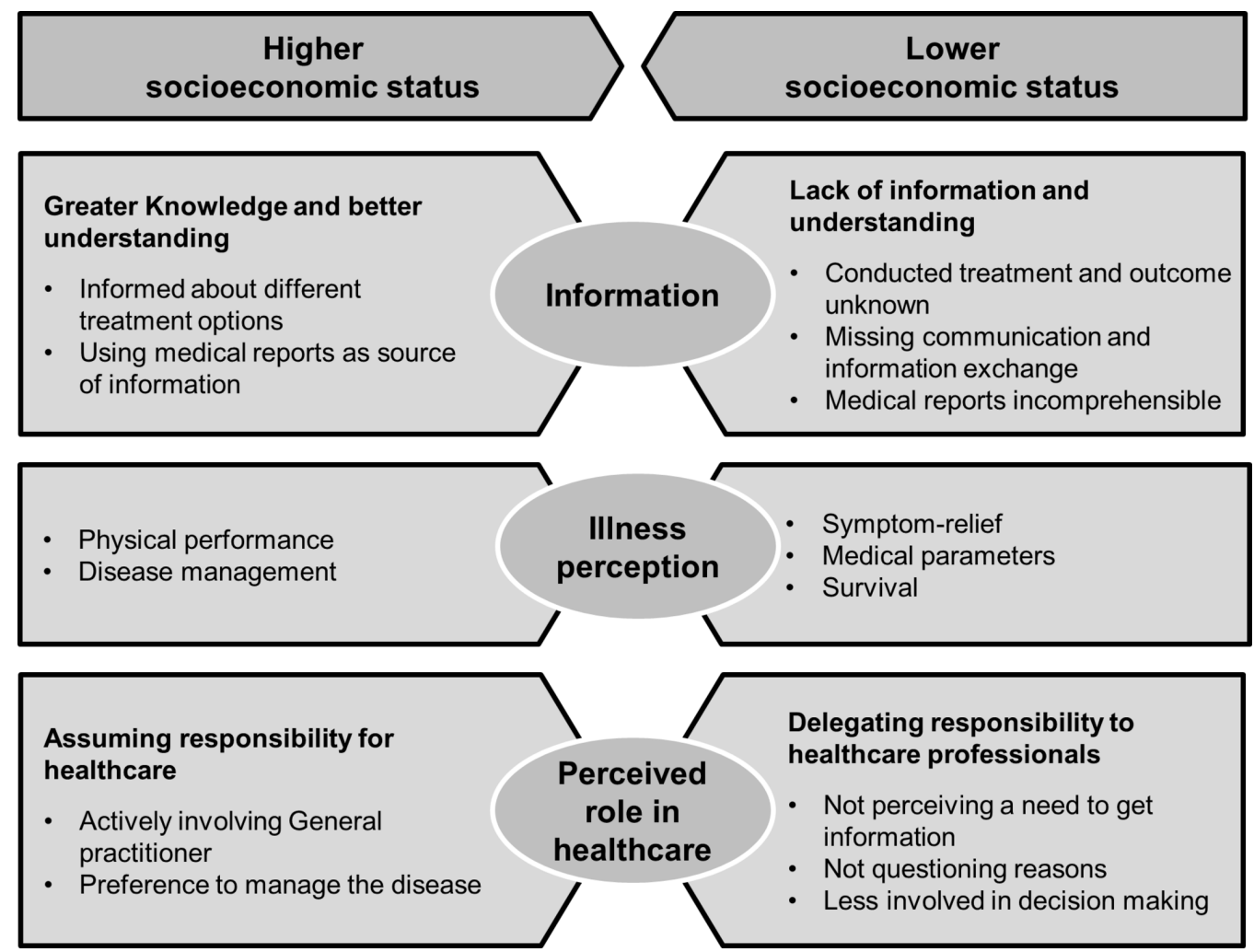

Figure 1 Three major themes derived from socioeconomic differences in patients' experiences with coronary heart disease treatment.

And as well, someone who is cognitively not that fit anymore, one does not understand at all what you are told. And that is sometimes not so nice. Well, but probably that's just our system, that is/which is not working, I think. (Mrs Koch, 62 years, lower SES)

You need to directly address the physicians; they do not have the time as well. You can notice that during the doctor's visits. Well, then it is clear. But otherwise you get an answer to any question; pleasant, polite, courteous. (Mr Schäfer, 71 years, higher SES)

Second, we found differences in patients' illness perceptions. Whereas lower-SES patients seemed to understand CHD through putting emphasis on symptoms and medical parameters measured through medical examinations, higher-SES patients focused on physical performance and disease management which requires knowledge about CHD.

Finally, we found differences in the patient's perceived role in healthcare. Lower-SES patients tended to delegate responsibility for treatment which became apparent, for example, by the patients not questioning the reasons for the decisions made, assuming that healthcare professionals are responsible for patients being taken seriously, not perceiving a need to obtain information even when lacking information, being less involved in decision-making, relying on physicians to coordinate care (referrals, medication), viewing themselves as only responsible for the retention of medical records and having a tendency to have general views rather than opinions. Contrastingly, higher-SES patients seem to feel more responsible for treatment, for example, focusing more strongly on disease management, having increased healthcare knowledge, making informed choices or actively involving their GP.

\section{DISCUSSION}

In this study, we elaborated three major themes from the patients' experiences with CHD treatment that were found to differ between patients of lower and higher SES: information, the patient's individual perception of CHD and their perceived role in healthcare. Regarding information, patients with higher SES had greater knowledge about treatment and could use medical records as sources of information. Regarding illness perception, patients with lower SES focused on improving symptoms and survival, while patients with higher SES focused on physical performance and disease management. Regarding the patient's perceived role in healthcare, patients with lower SES tended to delegate responsibility to healthcare professionals.

First, we found that lower-SES patients seem to lack knowledge about treatment compared with higher-SES patients, obtain less information and have problems understanding the information provided to them. This is in accordance with previous studies which found that knowledge about treatment was a barrier of utilisation and access for lower-SES patients, for example, to optimal 
oesophageal cancer care or reproductive healthcare. ${ }^{23} 24$ Especially in low-SES patients, it is well known that lack of information and knowledge results in low utilisation. ${ }^{25} 26$ This is probably due to the fact that patients of lower SES are generally given less information in healthcare. ${ }^{10}$ Especially with regard to CHD, studies showed that patients are given little information by health professionals, and therefore, wide information gaps exist for all patients with CHD. ${ }^{27}{ }^{28}$ Second, illness perception differs, as we found that lower-SES patients seem to focus more strongly on symptoms, survival and good results of physical check-ups in their illness perception, while higher-SES patients tend to focus on physical performance and disease management. The latter reveals more knowledge about CHD, and studies found that lack of knowledge regarding CHD is associated with both low SES and adherence. ${ }^{29-32}$ Therefore, we confirm the findings of another study that only lower SES patients felt excluded from cardiac rehabilitation due to their divergent health beliefs. ${ }^{17}$ This becomes particularly relevant as focusing on and improving physical performance are important for reducing cardiovascular mortality and inequalities in AMI mortality, independently of inequalities in access to healthcare. ${ }^{33}$ Finally, the perceived role in healthcare differed according to SES: higher-SES patients tended to assume responsibility for treatment, whereas lower-SES patients showed a tendency to relinquish responsibility. This latter finding was characterised by 'putting up with everything needed' and expecting to be told that 'everything is fine', with no further need to see a physician. Different responsibilities are becoming apparent through the decision-making process between the physician and the patient, as a study found that high-SES patients perceive their involvement as participating in the decision-making after exploring other options, whereas low-SES patients see themselves only being responsible for agreeing or disagreeing with the recommendation made. ${ }^{34}$ Therefore, we confirm another study which found that inequalities exist in the way that shared decision-making is more common in high-SES patients. ${ }^{16}$ However, the patient's assumed role is likely influenced by the physician, as a review found that physicians reported lower levels of facilitating shared decision-making with patients who were rated to be unable or unwilling to participate in decision-making from the physician's perspective or who showed limited awareness about their condition. ${ }^{35}$

Although we provide novel insights into the possible factors and mechanisms of socioeconomic differences in treatment, the study has several limitations. The generalisability might be limited as we only recruited elderly patients in the eastern part of Germany. Therefore, these results may not reflect the experiences of younger patients or those living in other regions. Importantly, data were generated in a country with statutory health insurance and financial concerns may better explain socioeconomic differences in treatment in other countries without universal healthcare systems. There might be transferability of some of our findings to settings of
CHD treatment with similar organisational and economic contexts. We increased the rigour of the study by taking the consolidation criteria for reporting qualitative research into account during the research process. ${ }^{36}$ Reflexivity was increased by using content analysis with a coding frame as well as coding the interviews and discussing the results with different researchers of a qualitative working group, and reporting on the process of interpretation within the Results section of the manuscript. Only a few patients reported problems with access to and utilisation of treatment. Throughout the narratives, only some experiences and viewpoints on treatment were found to differ according to SES. However, consideration of these aspects together led us to generate three data-driven major themes which may elucidate the possible mechanisms of socioeconomic inequalities in treatment but we did not find differences in treatment according to SES. Especially when assessing the patient's knowledge, information, illness perception and delegation of responsibility, it needs to be considered that we only analysed the patients' perspectives and viewpoints independently of the information that were given through communication by healthcare staff. Finally, as we operationalised SES dichotomously based on education and occupation, we simplified the continuum of social status. We did not collect data on income, as income presents a sensitive personal issue, especially in longitudinal studies, and for older people income is a less appropriate indicator for SES because it is highly affected by retirement and difficult to collect reliable information. ${ }^{37}$

Given that CHD is the leading cause of death worldwide, the generation of hypotheses regarding the potential factors underlying the socioeconomic differences in CHD treatment is essential for explaining and reducing these inequalities. The level of information and knowledge, individual illness perception and perceived role in healthcare can be the mechanisms that contribute to explain socioeconomic inequalities in CHD treatment and should be considered in further quantitative studies as mediating factors between SES and treatment. We conclude that improvement in patient-provider communication might be the key to reducing healthcare inequalities, as it may increase knowledge about treatment, improve the understanding of CHD and empower patients to assume responsibility in treatment which can improve engagement in treatment and utilisation.

Acknowledgements We acknowledge the patients who participated in this study and shared their healthcare experiences with us. We thank the staff at the Department of Cardiology at the University Hospital in Halle for their assistance with screening patients for this study, Niels Bormann for assisting with data collection, and the members of the qualitative research working group at the IMS, who helped with coding, discussing and evaluating the data. Finally, we acknowledge the financial support within the funding programme OpenAccess Publishing by the German Research Foundation (DFG).

Contributors SLS wrote the initial draft of this manuscript, collected data and analysed the transcripts. MR and AF conceptualised and designed the project, helped interpreting the data and critically reviewed the manuscript. All authors have read and approved the final version of the manuscript. 
Funding This work was supported by the Wilhelm Roux Programme of the Medical Faculty of Martin Luther University, Halle-Wittenberg with grant number FKZ: 28/40. Competing interests None declared.

Patient consent Obtained.

Ethics approval Ethical Review Committee of the Medical Faculty of Martin Luther University, Halle-Wittenberg (№. 2014-95).

Provenance and peer review Not commissioned; externally peer reviewed.

Data sharing statement Participants of this study were guaranteed that only the study research team would have access to the interviews and transcripts thus data are not available for sharing.

Open access This is an open access article distributed in accordance with the Creative Commons Attribution Non Commercial (CC BY-NC 4.0) license, which permits others to distribute, remix, adapt, build upon this work non-commercially, and license their derivative works on different terms, provided the original work is properly cited, appropriate credit is given, any changes made indicated, and the use is non-commercial. See: http://creativecommons.org/licenses/by-nc/4.0/.

\section{REFERENCES}

1. Nichols M, Townsend N, Scarborough P, et al. Cardiovascular disease in Europe: epidemiological update. Eur Heart $J$ 2013;34:3028-34.

2. GBD 2013 Mortality and Causes of Death Collaborators. Global, regional, and national age-sex specific all-cause and causespecific mortality for 240 causes of death, 1990-2013: A systematic analysis for the global burden of disease study 2013. Lancet 2015;385:117-71.

3. Benjamin EJ, Blaha MJ, Chiuve SE, et al. Heart disease and stroke statistics-2017 update: A report from the american heart association. Circulation 2017;135:e146-e603.

4. Khaing W, Vallibhakara SA, Attia J, et al. Effects of education and income on cardiovascular outcomes: A systematic review and metaanalysis. Eur J Prev Cardiol 2017;24:1032-42.

5. Havranek EP, Mujahid MS, Barr DA, et al. Social determinants of risk and outcomes for cardiovascular disease: A scientific statement From the American Heart Association. Circulation 2015;132:873-98.

6. de Mestral C, Stringhini S. Socioeconomic status and cardiovascular disease: an update. Curr Cardiol Rep 2017;19:115.

7. Finn SD, Gardin JM, Abrams J, et al. 2012 ACCF/AHA/ACP/AATS/ PCNA/SCAI/STS Guideline for the Diagnosis and Management of Patients With Stable Ischemic Heart Disease. J Am Coll Cardiol 2012;60:e44-e164.

8. Schröder SL, Richter M, Schröder J, et al. Socioeconomic inequalities in access to treatment for coronary heart disease: $A$ systematic review. Int J Cardiol 2016;219:70-8.

9. Pedersen M, Egerod I, Overgaard D, et al. Social inequality in phase II cardiac rehabilitation attendance: The impact of potential mediators. Eur J Cardiovasc Nurs 2018;17:345-55.

10. Verlinde E, De Laender N, De Maesschalck S, et al. The social gradient in doctor-patient communication. Int $J$ Equity Health 2012;11:12.

11. Ghisi GLM, Chaves G, Britto RR, et al. Health literacy and coronary artery disease: A systematic review. Patient Educ Couns 2018;101:177-84.

12. Sørensen K, Pelikan JM, Röthlin F, et al. Health literacy in Europe: comparative results of the European health literacy survey (HLS-EU). Eur J Public Health 2015;25:1053-8.

13. Hetemaa T, Keskimäki I, Manderbacka K, et al. How did the recent increase in the supply of coronary operations in Finland affect socioeconomic and gender equity in their use? J Epidemiol Community Health 2003;57:178-85.

14. Lemstra ME, Alsabbagh W, Rajakumar RJ, et al. Neighbourhood income and cardiac rehabilitation access as determinants of nonattendance and noncompletion. Can J Cardiol 2013;29:1599-603.
15. Perelman J, Shmueli A, McDonald KM, et al. Inequality in treatment use among elderly patients with acute myocardial infarction: USA, Belgium and Quebec. BMC Health Serv Res 2009;9:130.

16. Manderbacka K. Exploring gender and socioeconomic differences in treatment of coronary heart disease. Eur J Public Health 2005;15:634-9.

17. Pedersen M, Overgaard D, Andersen I, et al. Experience of exclusion: A framework analysis of socioeconomic factors affecting cardiac rehabilitation participation among patients with acute coronary syndrome. Eur J Cardiovasc Nurs 2017;16:715-23.

18. Schröder SL, Fink A, Schumann N, et al. How socioeconomic inequalities impact pathways of care for coronary artery disease among elderly patients: study protocol for a qualitative longitudinal study. BMJ Open 2015;5:e008060.

19. Helfferich C. Die Qualität qualitativer Daten: Manual für die Durchführung qualitativer interviews. 3rd ed. Wiesbaden: VS Verlag für Sozialwissenschaften, 2009.

20. Destatis. Demografische standards. 2017 https://www.destatis.de/ DE/Methoden/DemografischeRegionaleStandards/DemografischeSta ndardsInfo.html (accessed 16 Jul 2018).

21. Hoffmeyer-Zlotnik J. "Stellung im Beruf" als ersatz für eine berufsklassifikation zur ermittlung von sozialem prestige. In. ZUMA Nachrichten 2003;53:114-27.

22. Schreier M. Qualitative content analysis in practice. Los Angeles. London, New Dehli, Singapore, Washington DC: Sage, 2012.

23. Zimmerman MS, Poverty I, Healthcare R. Assessing the Reasons for Inequity between Income Groups. Soc Work Public Health 2017;32:210-21.

24. Lineback CM, Mervak CM, Revels SL, et al. Barriers to accessing optimal esophageal cancer care for socioeconomically disadvantaged patients. Ann Thorac Surg 2017;103:416-21.

25. Czarny MJ, Nathan AS, Yeh RW, et al. Adherence to dual antiplatelet therapy after coronary stenting: a systematic review. Clin Cardiol 2014;37:505-13.

26. Dankner R, Drory Y, Geulayov G, et al. A controlled intervention to increase participation in cardiac rehabilitation. Eur J Prev Cardiol 2015;22:1121-8

27. Nolan MT, McKee G. Is knowledge level of coronary heart disease and risk factors among post-percutaneous coronary intervention patients adequate?. J Cardiovasc Nurs 2016;31:E1-E9.

28. Nunes SRT, Rego G, Nunes R. Right or duty of information: a habermasian perspective. Nurs Eth 2016;23:36-47.

29. Kayaniyil S, Ardern Cl, Winstanley J, et al. Degree and correlates of cardiac knowledge and awareness among cardiac inpatients. Patient Educ Couns 2009;75:99-107.

30. Tchicaya A, Lorentz N, Demarest S, et al. Persistence of socioeconomic inequalities in the knowledge of cardiovascular risk factors five years after coronary angiography. Eur J Cardiovasc Nurs 2018;17:136-47.

31. Fennessy MM, Devon HA, Ryan C, et al. Changing illness perceptions and adherence to dual antiplatelet therapy in patients with stable coronary disease. J Cardiovasc Nurs 2013;28:573-83.

32. Kucukarslan SN. A review of published studies of patients' illness perceptions and medication adherence: lessons learned and future directions. Res Social Adm Pharm 2012;8:371-82.

33. Alter DA, Franklin B, Ko DT, et al. Socioeconomic status, functional recovery, and long-term mortality among patients surviving acute myocardial infarction. PLoS One 2014;8:e65130.

34. Smith SK, Dixon A, Trevena L, et al. Exploring patient involvement in healthcare decision making across different education and functional health literacy groups. Soc Sci Med 2009;69:1805-12.

35. Pollard S, Bansback N, Bryan S. Physician attitudes toward shared decision making: A systematic review. Patient Educ Couns 2015;98:1046-57.

36. Tong A, Sainsbury P, Craig J. Consolidated criteria for reporting qualitative research (COREQ): a 32-item checklist for interviews and focus groups. Int J Qual Health Care 2007;19:349-57.

37. Galobardes B, Shaw M, Lawlor DA, et al. Indicators of socioeconomic position (part 1). J Epidemiol Community Health 2006;60:7-12. 